\title{
Neurological Complications of COVID-19 and Possible Neuroinvasion Pathways: A Systematic Review
}

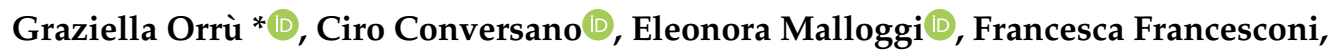 \\ Rebecca Ciacchini and Angelo Gemignani \\ Department of Surgical, Medical and Molecular \& Critical Area Pathology, University of Pisa, via Savi 10, \\ 56126 Pisa, Italy; ciro.conversano@unipi.it (C.C.); e.malloggi1@studenti.unipi.it (E.M.); \\ f.francesconi2@studenti.unipi.it (F.F.); rebecca.ciacchini@gmail.com (R.C.); angelo.gemignani@unipi.it (A.G.) \\ * Correspondence: graziella.orru@unipi.it
}

Received: 4 August 2020; Accepted: 10 September 2020; Published: 14 September 2020

\begin{abstract}
The Coronavirus Disease 2019 (COVID-19) outbreak has shocked the whole world with its unexpected rapid spread. The virus responsible for the disease, the Severe Acute Respiratory Syndrome Coronavirus 2 (SARS-CoV-2), enters host cells by means of the envelope spike protein, which binds to angiotensin-converting enzyme 2 receptors. These receptors are highly expressed in heart, lungs, respiratory tract epithelium, endothelial cells and brain. Since an increasing body of significant evidence is highlighting a possible neuroinvasion related to SARS-CoV-2, a state of the art on the neurological complications is needed. To identify suitable publications, our systematic review was carried out by searching relevant studies on PubMed and Scopus databases. We included studies investigating neurologic manifestations of SARS-CoV-2 in patients over 18. According to the analyzed studies, the most frequent disorders affecting central nervous system (CNS) seem to be the following: olfactory and taste disorders, ischemic/hemorrhagic stroke, meningoencephalitis and encephalopathy, including acute necrotizing encephalopathy, a rare type of encephalopathy. As regards the peripheral nervous system (PNS), Guillain-Barré and Miller Fisher syndromes are the most frequent manifestations reported in the literature. Important clinical information on the neurological manifestations of SARS-CoV-2 would help clinicians raise awareness and simultaneously improve the prognosis of critically ill patients.
\end{abstract}

Keywords: COVID-19; SARS-CoV-2; neurologic complications

\section{Introduction}

Since it was first announced in December 2019 in Wuhan, China, the Coronavirus Disease 2019 (COVID-19) has rapidly spread all over the world, and, on 11 March 2020, the World Health Organization (WHO) declared COVID-19 as a pandemic disease [1]. Genomic analyses showed that the virus responsible for COVID-19, the Severe Acute Respiratory Syndrome Coronavirus 2 (SARS-CoV-2), belongs to a beta-coronavirus cluster, along with the SARS-CoV and the Middle East Respiratory Syndrome Coronavirus (MERS-CoV) [2]. Infection in humans often leads to severe clinical symptoms and high mortality [3]. Clinical manifestations include respiratory symptoms and gastroenteric symptoms, with an incubation time ranging from two days to two weeks [4]. In particular, clinical characteristics of COVID-19 observed thus far are fever, dry cough, diarrhea, fatigue, dyspnea and pneumonia with peculiar lungs radiological features, such as bilateral multiple lobular and subsegmental areas of consolidations. Its severity ranges from asymptomatic manifestation to death [5]. Although much is known about the mortality rate and the main clinical manifestations 
of the disease, much less is known about its pathobiology. A probable course of events can be postulated according to past studies related to other coronavirus clusters (i.e., SARS-CoV). In this regard, evidence suggests that the virus enters host cells via the envelope spike (S) protein, which binds to angiotensin-converting enzyme 2 (ACE 2) receptor [6,7]. ACE 2 is known to be expressed in many organs, including heart, kidneys, liver, brain and abundantly in the epithelia of the lungs, respiratory tract, small intestine and endothelial cells [8]. Although SARS-CoV and SARS-CoV-2 have the same cellular target, SARS-CoV-2 shows higher binding affinity to ACE 2 [9]. There are other receptors that can mediate the entry of SARS-CoV-2 [7], e.g., transmembrane serine protease 2 (TMPRSS2) [10,11], sialic acid receptors [12,13] and extracellular matrix metalloproteinase inducer (CD147) [14]. Since COVID-19 was first identified in humans, scientific literature has dramatically increased, also reporting extra respiratory symptoms, among them neurologic complications. There is a huge body of evidence that points out to neurotropism as a characteristic of coronaviruses [6] and burgeoning studies have recently observed neurologic effects of SARS-CoV-2 on animal models, including non-human primates, mice, rats, hamsters and ferrets [15]. Furthermore, given the increasing amount of clinical data reporting neurologic involvement of SARS-CoV-2 $[16,17]$ and post-mortem histologic studies revealing viral particles presence in human brain tissue [18], the urge to increase the awareness of the neurologic manifestations related to COVID-19 is of paramount importance. The purpose of the present study was to provide a systematic review of the literature, gathering relevant studies on the neurologic complications of COVID-19 on both the central nervous system (CNS) and the peripheral nervous system (PNS) in order to enhance a better management of infection-related neurological complications of affected patients.

\section{Materials and Methods}

This systematic review was carried out according to the Preferred Reporting Items for Systematic Review and Meta-Analysis guidelines (PRISMA, Figure 1) [19]. The search strategy consisted of three phases: (1) Identification: PubMed and Scopus databases were systematically searched in June 2020 with the following keywords: "brain" OR "nervous system" OR "central nervous system" OR "peripheral nervous system" OR "neurologic symptoms" OR "neurologic disorders" AND "COVID-19". (2) Screening: A manual screening of the articles retrieved in phase 1 was conducted by evaluating titles and abstracts only. (3) Eligibility: Full-text articles were assessed on the basis of the following eligibility criteria: (i) individuals over 18 years old; (ii) case reports; (iii) retrospective studies; (iv) case-control studies; (v) in-press articles; and (vi) articles published in international peer-reviewed journals. In addition to the electronic databases search, references list of each study was scanned to ensure a comprehensive literature search. Only English-written articles were included. Uncorrected proofs were excluded. 


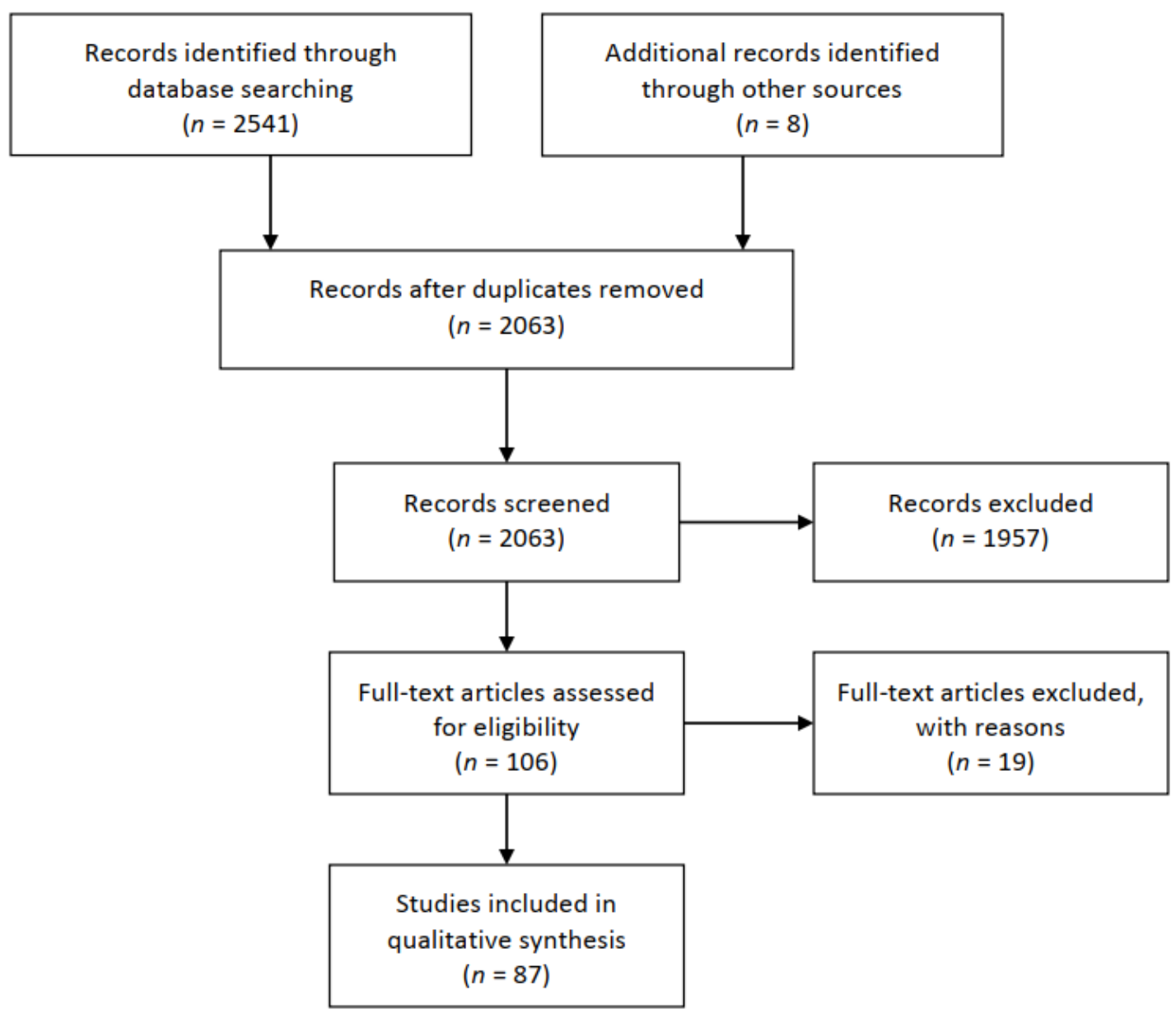

Figure 1. Flow chart of the studies selection.

\section{Results and Discussion}

Through the electronic databases search, 2541 publications were found. After manual removal of duplicates, 2063 articles were screened. Based on title and abstract reading, 1957 studies were excluded. In total, 106 full-text articles were assessed for eligibility. Among these, 19 studies were excluded for the following reasons: uncorrected proofs $(n=16)$; study protocol not started yet $(n=1)$; commentary study $(n=1)$; and vade mecum for neurologists $(n=1)$ to help them manage patients in the COVID-19 era. Finally, 87 studies met the inclusion criteria described above and were included (Figure 1).

\subsection{Categorization and Characteristics of the Selected Studies}

The studies included were subsequently divided into two categories: (1) studies concerning COVID-19 effects on the CNS $(n=68)$; and (2) those concerning COVID-19 effects on the PNS $(n=21)$, which are fully reported in the Supplementary Materials (Table S1 and Table S2). In total, 6890 patients were included in the studies. Among the 68 studies on the CNS effects, 46 were case reports [16,17,20-63], followed by 10 retrospective studies [64-73], 4 observational cohort studies [74-77], 3 prospective studies [78-80], 3 case-control studies [81-83] and 2 cross-sectional studies [84,85]. Among the 21 studies regarding PNS disorders, there were 19 case reports [86-104], 1 prospective study [78] and 1 retrospective study [68]. Two studies reported both CNS and PNS effects of COVID-19 [68,78].

Due to the vast heterogeneity of the studies design as regards to statistical validity, tools for assessing studies quality were used, based on "Algorithm for classifying study design for questions of 
effectiveness" (Algorithm for classifying study design for questions of effectiveness, (www.nice.org.uk): https://www.sign.ac.uk/assets/study_design.pdf).

\subsubsection{Effects of SARS-CoV-2 on CNS}

Studies regarding CNS complications caused by SARS-CoV-2 infection are summarized in Table 1. Primary outcomes of the studies were classified in macrocategories regarding the main neurological complications.

Table 1. Categorization of the studies concerning SARS-CoV-2 effects on the CNS: (a) Stroke; (b) Smell and taste disorders (STDs); (c) Encephalopathy; (d) Meningoencephalitis; (e) Seizures; and (f) Other Neurological Conditions.

\begin{tabular}{|c|c|}
\hline Article/Sample (n) & $p$-Value/rho Value/Odd Ratio \\
\hline \multicolumn{2}{|r|}{ (a) Stroke } \\
\hline Al Saiegh et al. [20] $n=2$ & N.A. \\
\hline Avula et al. [64] $n=4$ & N.A. \\
\hline Barrios-Lòpez et al. [22] $n=4$ & N.A. \\
\hline Beyrouti et al. [24] $n=6$ & N.A. \\
\hline Benger et al. [23] $n=5$ & N.A. \\
\hline Co et al. [25] $n=1$ & N.A. \\
\hline Craen et al. [26] $n=1$ & N.A. \\
\hline Deliwala et al. [27] $n=1$ & N.A. \\
\hline Frisullo et al. [33] $n=1$ & N.A. \\
\hline Garaci et al. [35] $n=1$ & N.A. \\
\hline Goldberg et al. [37] $n=1$ & N.A. \\
\hline Haddadi et al. [38] $n=1$ & N.A. \\
\hline Helms et al. [82] $n=58$ & N.A. \\
\hline Kandemirli et al. [65] $n=23$ & N.A. \\
\hline Karadaş et al. [74] $n=239$ & N.A. \\
\hline Lu et al. [67] $n=304$ & N.A. \\
\hline Manganelli et al. [44] $n=3$ & N.A. \\
\hline & Stroke prevalence $(p=0.03)$ \\
\hline Mao et al. [68] $n=214$ & Major Complications $(p=0.02)$ \\
\hline Morassi et al. [69] $n=6$ & N.A. \\
\hline Muhammad et al. [47] $n=1$ & N.A. \\
\hline Oxley et al. [51] $n=5$ & N.A. \\
\hline Radmanesh et al. [71] $n=11$ & N.A. \\
\hline Reichard et al. [52] $n=1$ & N.A. \\
\hline Sharifi-Razavi et al. [54] $n=1$ & N.A. \\
\hline Shoskes et al. [55] $n=1$ & N.A. \\
\hline Tunç et al. [57] $n=4$ & N.A. \\
\hline Viguier et al. [58] $n=1$ & N.A. \\
\hline Zhai et al. [62] $n=1$ & N.A. \\
\hline \multicolumn{2}{|r|}{ (b) STDs } \\
\hline Beltrán-Corbellini et al. [81] $n=79$ & $p=0.003:$ STDs more frequent among cases \\
\hline Carignan et al. [82] $n=134$ & $p<0.001$ : STDs more frequent among cases as compared to controls \\
\hline Dell'Era et al. [84] $n=355$ & $p<0.001$ : full recovery after 14 days \\
\hline Gane et al. [34] $n=1$ & N.A. \\
\hline & $p<0.001$ : association between anosmia and dysgeusia \\
\hline Giacomelli et al. [85] $n=59$ & $p=0.036:$ STDs more frequent among $\mathrm{F}$ \\
\hline & $p=0.035$ STDs more frequent among younger patients \\
\hline Gilani et al. [36] $n=8$ & N.A. \\
\hline Hjelmeseth and Skaare $[40] n=60$ & N.A. \\
\hline Hopkins et al. [75] $n=382$ & $p<0.001$ : symptoms improvement after 2 weeks \\
\hline Hornuss et al. [83] $n=45$ & $p<0.001:$ STDs more frequent among cases \\
\hline Lechien et al. [66] $n=417$ & $p<0.001$ : anosmia and dysgeusia and more frequent among $\mathrm{F}$ \\
\hline
\end{tabular}


Table 1. Cont.

\begin{tabular}{|c|c|}
\hline Article/Sample (n) & $p$-Value/rho Value/Odd Ratio \\
\hline Lee et al. [79] $n=3191$ & $\begin{array}{l}p=0.01: \text { more common in } \mathrm{F} \\
p<0.001 \text { more common in young patients }\end{array}$ \\
\hline Melley et al. [46] $n=1$ & N.A. \\
\hline Ollarves-Carrero et al. [49] $n=1$ & N.A. \\
\hline Ottaviano et al. [50] $n=6$ & N.A. \\
\hline Speth et al. [80] $n=103$ & $\begin{array}{l}p<0.001: \text { prevalence of STDs } \\
\text { OR }=0.96: \text { negative correlation between STDs and older age } \\
O R=2.46: \text { positive correlation between STDs and F } \\
\rho=0.87: \text { correlation between severity of taste and olfactory disorders }\end{array}$ \\
\hline Spinato et al. [73] $n=202$ & $p=0.02:$ STDs more frequent among women \\
\hline Vaira et al. [76] $n=72$ & $\begin{array}{l}p=0.003: \text { taste disorders worse in older patients }(\text { age } \geq 50) \\
p=0.001: \text { STDs improvement after } 15 \text { days from the onset }\end{array}$ \\
\hline \multirow[t]{2}{*}{ Vaira et al. [77] $n=345$} & $p=0.000:$ symptoms improvement after one or two weeks \\
\hline & (c) Encephalopathy \\
\hline Filatov et al. [30] $n=1$ & N.A. \\
\hline Flamand et al. [31] $n=1$ & N.A. \\
\hline Franceschi et al. [32] $n=2$ & N.A. \\
\hline Hayashi et al. [39] $n=1$ & N.A. \\
\hline Kaya et al. [42] $n=1$ & N.A. \\
\hline Kishfy et al. [43] $n=2$ & N.A. \\
\hline Lu et al. [67] $n=304$ & N.A. \\
\hline Poyiadji et al. [17] $n=1$ & N.A. \\
\hline Radmanesh et al. [71] $n=11$ & N.A. \\
\hline Rogg et al. [53] $n=1$ & N.A. \\
\hline Scullen et al. [72] $n=76$ & N.A. \\
\hline \multicolumn{2}{|r|}{ (d) Meningoencephalitis } \\
\hline Al-olama et al. [21] $n=1$ & N.A. \\
\hline Duong et al. [28] $n=1$ & N.A. \\
\hline Moriguchi et al. [16] $n=1$ & N.A. \\
\hline Reichard et al. [52] $n=1$ & N.A. \\
\hline Wong et al. [59] $n=1$ & N.A. \\
\hline Ye et al. [60] $n=1$ & N.A. \\
\hline Zoghi et al. [63] $n=1$ & N.A. \\
\hline \multicolumn{2}{|r|}{ (e) Seizures } \\
\hline Fasano et al. [29] $n=1$ & N.A. \\
\hline Lu et al. [67] $n=304$ & N.A. \\
\hline Somani et al. [56] $n=2$ & N.A. \\
\hline \multicolumn{2}{|r|}{ (f) Other Neurological Conditions * } \\
\hline Kadono et al. [41] $n=1$ & N.A. \\
\hline Karadas et al. [78] $n=239$ & N.A. \\
\hline Mawhinney et al. [45] $n=1$ & N.A. \\
\hline Noro et al. [48] $n=1$ & N.A. \\
\hline Petrescu et al. [70] $n=36$ & N.A. \\
\hline Scullen et al. [72] $n=76$ & N.A. \\
\hline Zanin et al. [61] $n=1$ & N.A. \\
\hline Mao et al. [68] $n=214$ & $p<0.001$ \\
\hline
\end{tabular}

An increasing body of significant evidence reported olfactory and taste disorders as specific clinical manifestations of SARS-CoV-2. In this context, a cross-sectional survey carried out by Giacomelli and colleagues [85] found that STDs were displayed in 20 out of 59 COVID-19 patients, most of whom were female and young. Twelve patients exhibited the symptoms at the onset of the disease and, among them, taste alterations were the most frequent (91\%). These findings were mostly confirmed by Lechien and colleagues [66] in a European retrospective study: $85.6 \%$ and $88.0 \%$ of patients reported olfactory and 
gustatory dysfunctions, respectively, and a significant association between both disorders was detected $(p<0.001)$. The early olfactory recovery frequency was $44.0 \%$. STDs prevalence was more common among females. It is worth noting that allergic rhinitis was the most frequent pre-existing medical condition among hyposmic and anosmic patients. These results were confirmed by a prospective cross-sectional study conducted by Speth and colleagues [80], in which the prevalence of olfactory disorders was around $61.2 \%$ and symptoms severity was correlated with the severity of taste disorders $(p<0.001)$. Furthermore, STDs strongly correlated with younger age $(p=0.007)$ and female sex $(p=0.56)$. Similarly, in their cross-sectional study, Dell'Era and colleagues [84] conducted a survey to detect chemosensory disorders prevalence among COVID-19 patients. They found that 249 out of 355 patients reported STDs; moreover, 31 of them reported these symptoms at the onset of COVID-19. Patients' mean age was 50.

In their case-control study, Beltrán-Corbellini and colleagues [81] found STDs (especially anosmia) to be more present among COVID-19 patients (39.2\%) compared to the control group (patients with influenza) $(12.5 \%)(p=0.003)$. Symptoms mean duration was one week with acute onset in $70.9 \%$ of the cases. COVID-19 patients with STDs were younger than those without STDs. Another case-control study carried out by Carignan and colleagues [82] described 69 patients with anosmia and 85 with dysgeusia out of 134 COVID-19 patients (mean age of 57.1). The frequency of chemosensory disorders was significantly higher among COVID-19 patients, compared to the control group $(p<0.001)$. Similarly, Hornuss and colleagues [83] detected a significantly higher prevalence of anosmia in a sample of COVID-19 patients ( $40 \%$ of 45 patients) as compared to control group $(p<0.001)$.

Spinato and colleagues [73] conducted a retrospective study reporting 130 patients out of 202 affected by STDs with different onset timing: symptoms occurred before other clinical manifestations in $11.9 \%$ of the patients, simultaneously with COVID-19 onset in $22.8 \%$ and after other symptoms in $26.7 \%$ of the subjects. STDs were the only symptoms of COVID-19 in $3.0 \%$ of the sample.

A prospective study, conducted by Lee and colleagues [79] on 3191 patients, reported STDs in $15.3 \%$ of patients at an early stage of COVID-19 and in $15.7 \%$ of asymptomatic patients or patients with mild disease severity. STDs were more frequently observed among females and young subjects.

Hopkins and colleagues [75] administered an online questionnaire to 382 COVID-19 patients to investigate the prevalence of smell and taste alterations and their course: $86.4 \%$ reported complete anosmia, which was almost reversed one week later in $80.1 \%$, unchanged in $17.6 \%$ and worsened in $1.9 \%$ of the patients. Overall, $17.3 \%$ of the subjects reported persistent anosmia lasting from one to over four weeks.

Vaira and colleagues conducted two observational studies [76,77] to detect chemosensory dysfunctions among individuals who had contracted SARS-CoV-2 infection. In their first study, the authors recruited a sample of 72 COVID-19 patients treated at University Hospital of Sassari (mean age 49.2); among them, 53 reported STDs, 30 of whom reported both anosmia and dysgeusia. In the other study, the authors involved four Italian hospitals, reporting chemosensory disorders in 256 out of 345 patients. In total, $79.3 \%$ of them reported both olfactory and taste alterations, $8.6 \%$ isolated olfactory disorders and $12.1 \%$ isolated taste disorders.

These results are further supported by different case reports: seven studies $[34,36,40,46,49,50]$ reported patients with olfactory and taste disorders as the only symptoms of COVID-19, apart from some subjects who also had other symptoms: myalgia, mild fever and cough [50], dyspnea, cough and chest tightness [46]. Most individuals were middle-aged and had no comorbidities, except for one subject who had atrial fibrillation and had undergone surgery for gastric ulcer [40] and another one who had hypertension, hyperlipidemia and asthma [46]. Patients mostly exhibited symptoms at the onset of the disease. Symptoms duration was 15 days on average.

The prevalence of the main neurologic features associated to COVID-19 was described by Karadass and colleagues [78] in a cohort of 239 patients (mean age 46.46). Eighty-three patients displayed neurologic symptoms: headache was reported by 64 patients, dizziness in 16, 23 patients had impaired consciousness and 9 of them exhibited cerebrovascular disorders. 
$\mathrm{Lu}$ and colleagues [67] carried out a multicenter retrospective study, enrolling 304 COVID-19 patients, 108 of whom had severe infection. Two patients had seizure-like symptoms during hospitalization, which were ascribed to acute stress reaction and hypocalcemia, and 84 had brain insults or metabolic imbalances.

In a cohort of 214 patients observed by Mao and colleagues [68], 78 had neurologic symptoms. Among them, symptoms were ascribable to CNS lesions such as dizziness, headache, impaired consciousness, acute cerebrovascular disease, ataxia and seizure (in order of prevalence). These patients were among those who displayed severe infection, older age, comorbidities, especially hypertension, and had fewer classical COVID-19 symptoms, compared to patients with mild disease severity.

Helms and colleagues [74] found neurological manifestations in 49 out of 58 patients admitted to hospital for acute respiratory distress syndrome caused by COVID-19. Patients exhibited agitation, confusion, corticospinal tract signs and dysexecutive syndrome. Magnetic Resonance Imaging (MRI) revealed leptomeningeal enhancement, perfusion abnormalities and cerebral ischemic stroke. Seven patients had pre-existing neurological conditions such as transient ischemic attack, partial epilepsy and mild cognitive impairment.

In their retrospective study, Kandemirli and colleagues [65] detected neurologic symptoms in 50 out of 235 COVID-19 patients admitted to intensive care unit, 27 of whom underwent MRI: 12 patients had abnormal MRI results; 10 of them had fluid-attenuated inversion recovery (FLAIR) signal abnormality and 2 had brain thrombosis and acute infarction.

MRI abnormalities were also reported by Radmanesh and colleagues [71] in 11 middle-aged patients with severe infection. Neurological complications included diffuse leukoencephalopathy and microhemorrhages in juxtacortical and callosal white matter. Patients had several pre-existing medical conditions, mostly regarding the cardiovascular system.

Two retrospective studies described critical stroke conditions related to COVID-19: Avula and colleagues [64] reported four patients exhibiting radiographic evidence of acute stroke, while Morassi and colleagues [69] observed five patients with ischemic and hemorrhagic stroke, with one patient developing encephalopathy before stroke; five of them died and one remained neurologically impaired. All subjects included in the two studies had previous vascular risk factors and their mean age was 81 in the former study and 69 in the latter.

Scullen and colleagues [72] carried out a retrospective study in which they categorized neurologic complications associated to COVID-19 based on brain imaging or electroencephalography (EEG) of 76 patients; 27 of them had positive neurological examination which revealed encephalopathy in 20 cases, acute necrotizing encephalopathy in 2 patients and vasculopathy in 5 patients.

An exhaustive systematic retrospective study was conducted by Petrescu and colleagues [70] who shed light on important EEG findings associated with SARS-CoV-2 infection. EEG was performed in 36 patients with an age ranging from 43 to 97 years. EEG recordings were normal to mildly altered in $57.5 \%$ of patients, while in $42.5 \%$ EEG alterations were observed: abnormalities were moderate in $10 \%$ of the patients, severe in $20 \%$ and critical in $12.5 \%$. The most frequent comorbidities among patients were hypertension, diabetes mellitus, cardiomyopathy, renal failure and dementia.

The aforementioned findings are corroborated by a huge number of case reports.

Filatov and colleagues [30] reported a 74-year-old patient with encephalopathy and EEG abnormalities exhibiting inability to speak and follow commands as neurologic complications of COVID-19. The patient had several pre-existent cardiovascular pathologies and Parkinson's disease. EEG abnormalities were detected by Flamand and colleagues, too [31]. The authors reported an 80-year-old woman exhibiting motor seizures; EEG revealed paroxysm with a triphasic aspect, suggesting a toxic/metabolic encephalopathy linked to COVID-19. Clonic seizures with loss of consciousness was reported as a COVID-19 onset symptom by Fasano and colleagues [29]. The patient was a 54-year-old man and had no relevant medical history. De novo status epilepticus was also reported by Somani and colleagues [56] in two COVID-19 patients. One patient was a 49-year-old woman with a past medical history of rheumatoid arthritis, schizoaffective and conversion disorder; 
the other patient was a 79-year-old woman who developed myoclonic status epilepticus with coma and then died. She had a past medical history of encephalocele and hydrocephalus. Brain imaging of both patients was unrevealing. Kadono and colleagues [41] also reported a case of seizures as secondary symptoms of SARS-CoV-2 infection. The patient was a 44-year-old man, who presented twitch on hand and face; furthermore, computerized tomography (CT) revealed right temporal lobe edema. The man had a past medical history of epilepsy following cerebral venous thrombosis. Similarly, Zanin and colleagues [61] reported the case of a 54-year-old woman exhibiting loss of consciousness and seizures concomitant with SARS-CoV-2 infection. Anosmia and ageusia were also present. MRI revealed demyelinating lesions, but no traces of virus RNA were found in CSF. The patient had a past medical history of anterior communicating artery aneurysm.

Moriguchi and colleagues [16] reported the first case of meningitis related to COVID-19 in a man of 24 years. Interestingly, SARS-CoV-2 RNA was not present in nasopharyngeal swab, but it was detected in cerebrospinal fluid (CSF) sample.

Several studies reported patients developing ischemic or hemorrhagic stroke secondary to SARS-CoV-2 infection. Viguier and colleagues [58] described a 73-year-old COVID-19 patient with no relevant medical history exhibiting acute ischemic stroke with aphasia and right hemiparesis as main clinical manifestations. Al-Saiegh and colleagues [20] described two patients affected by COVID-19 with concurrent neurologic symptoms. The first one, a 31-year-old man, exhibited headache and loss of consciousness, which were found to be clinical manifestations of subarachnoid hemorrhage. The other patient, a 62-year-old woman, had an ischemic stroke with hemorrhagic conversion. As already reported above with reference to another study [60], CSF samples were negative for SARS-CoV-2. Goldberg and colleagues [37] also reported the case of a 64-year-old man diagnosed with COVID-19 with concomitant acute ischemic stroke. He had a medical history of hypertension. Beyrouti and colleagues [24] reported six patients who exhibited multi-territory brain infarcts, venous thrombosis and ischemic stroke after a period ranging from 8 to 24 days from SARS-CoV-2 infection onset. Their mean age was 69.2 and most of them had cardiovascular risk factors. Tunç and colleagues [57] reported four patients aged between 45 and 77 affected by COVID-19 diagnosed with acute ischemic stroke. Three of them had a medical history of hypertension and the fourth one had diabetes. Deliwala and colleagues [27] described the case of a 31-year-old woman with no pre-existent clinical conditions exhibiting confusion and encephalopathy after diagnosis of COVID-19. Brain imaging revealed cortical ischemic stroke in right middle cerebral artery territory. Oxley and colleagues [51] reported five cases of large-vessel stroke in COVID-19 patients whose mean age was 40.4. Three of them (all males) had risk factors for stroke. Similarly, Barrios-López and colleagues [22] reported two male patients who developed ischemic stroke after SARS-CoV-2 infection. One patient was 50 years old and had a past medical history of diabetes mellitus and obesity. The other patient was 67 years old with no pre-existing pathologies. Other three studies described the cases of ischemic stroke concomitant with COVID-19: the patient reported by Co and colleagues [25] was a 62-year-old woman with several pre-existing pathologies such as hypertension, diabetes, dyslipidemia and transient ischemic attack; the patient reported by Frisullo and colleagues [33] was a young woman with no concomitant pathologies, while Zhai and colleagues' [62] patient was a 79-year-old-man. Cerebrovascular complications caused by SARS-CoV-2 infection were also reported by Garaci and colleagues [35]. The authors described a 44-year-old woman with negative past medical history, who developed thrombosis of the superior vena cava, pulmonary artery and deep intracerebral venous thrombosis.

Numerous cases of encephalitis/encephalopathy associated with SARS-CoV-2 infection were reported, too. Ye and colleagues [60] observed a COVID-19 male patient exhibiting confusion and diagnosed with encephalitis; however, no traces of SARS-CoV-2 RNA in CSF were found. Duong and colleagues [28] reported the case of a 41-year-old woman diagnosed with meningoencephalitis as neurologic complication of COVID-19, showing disorientation and hallucinations. Symptoms evolved in lethargic status and then agitation. Reichard and colleagues [52] carried out post-mortem analysis in a 71-year-old man who died of COVID-19 complications, reporting acute disseminated 
encephalomyelitis and neocortical micro-infarcts. The patient had previously been diagnosed with ischemic heart disease caused by coronary artery atherosclerosis. Hayashi and colleagues [39] reported the first case of mild encephalitis/encephalopathy with a reversible splenial lesion in a 75-year-old-man with a history of mild Alzheimer's disease. The first case of acute necrotizing encephalopathy as a complication of COVID-19 was reported by Poyiadji and colleagues [17]. The authors described a woman in her late fifties displaying altered mental status. Further investigation through brain imaging revealed hemorrhagic rim enhancing lesions within the bilateral thalami, medial temporal lobes and subinsular regions, coherent with the diagnosis of this rare type of encephalopathy. Furthermore, Zoghi and colleagues [63] described the case of a 21-year-old man who developed encephalomyelitis with atypical demyelination pattern revealed by MRI. The patient had negative medical history.

Kaya and colleagues [42] described a young man with COVID-19 presenting cortical blindness, apathia and inability to respond to commands. MRI and diffusion weighted imaging (DWI) revealed posterior reversible leukoencephalopathy (PRES). His medical history was negative for relevant pre-existing pathologies. Two cases of PRES concomitant with SARS-CoV-2 infection were also reported by Franceschi and colleagues [32]. Patients were a 48-year-old man with obesity and a 67-year-old woman with past medical history of hypertension, diabetes, coronary artery disease, gout and asthma. Another case of PRES was reported by Rogg and colleagues [53] in a 59-year-old COVID-19 patient who subsequently died. He had no relevant past history. Similarly, Kishfy and colleagues [43] described two COVID-19 patients (aged 58 and 67, respectively) who developed PRES. They had past medical histories of hyperlipidemia and of hypertension, diabetes and obesity.

A case of CSF negative for SARS-CoV-2, despite COVID-19 diagnosis with concomitant brain damage, was reported by Muhammad and colleagues [47]. The patient was a 60-year-old woman with left frontal subarachnoid hemorrhage exhibiting with loss of consciousness. Subarachnoid hemorrhage was also reported by Craen and colleagues [26] as a complication of COVID-19 in a 66-year-old woman with a past medical history of diabetes, hypertension and hyperlipidemia. A rare case of bilateral basal ganglia hemorrhage was detected by Haddadi and colleagues [38] in a 54-year-old woman who had contracted SARS-CoV-2 infection and with a past medical history of diabetes, hypertension, lumbar spinal laminectomy and fusion surgery. Microhemorrhages were revealed by MRI in corpus callosum, basal ganglia and brainstem in a 69-year-old COVID-19 patient with a history of hypertension, chronic kidney disease, and hypothyroidism reported by Shoskes and colleagues [55]. Sharifi-Razavi and colleagues [54] reported the case of a 79-year-old man exhibiting loss of consciousness caused by a massive intracerebral hemorrhage secondary to SARS-CoV-2 infection. He had no pre-existing medical conditions. Similarly, Benger and colleagues [23] reported a case series of five patients who developed intracerebral hemorrhage after contracting SARS-CoV-2 infection. They were aged between 41 and 64 and had several vascular risk factors, such as hypertension, past deep vein thrombosis and ischemic heart disease.

The case of a 36-year-old COVID-19-positive man presenting drowsiness and confusion was described by Al-olama and colleagues [21]. Symptoms were ascribable to meningoencephalitis complicated by intracerebral hematoma and subdural hematoma, revealed by brain imaging. CSF was found positive for SARS-CoV-2. No relevant medical history was reported.

Wong and colleagues [59] reported the case of a 40-year-old man who developed diplopia, limb ataxia, unsteady gait and nystagmus after contracting SARS-CoV-2 infection. MRI revealed brainstem inflammation, coherent with a diagnosis of rhombencephalitis. The patient had a medical history of glaucoma and hypertension. Brainstem lesion that led to depression of respiratory center was also reported by Manganelli and colleagues [44] in three patients. Two of them, a 66-year-old man and a 47-year-old woman, died a few days after the neurological examination.

Noro and colleagues [48] reported an interesting case of a fit 35-year-old woman who developed benign intracranial hypertension after contracting COVID-19. CSF was negative for SARS-CoV-2 infection. 
Interestingly, Mawhinney and colleagues [45] reported the first case of acute manic episode associated with SARS-CoV-2 infection. In fact, the authors described a 41-year-old man who developed severe headache followed by sexual disinhibition, elevated mood and delusions ten days after COVID-19 symptoms onset. Neurological examination was negative. Twenty-three days later, the patient returned to baseline mental status. He had no comorbidities, but his sister had positive history for postpartum psychosis and was diagnosed with bipolar disorder.

Given the heterogeneity among the study designs, conducting a meta-analysis was not possible, but a preliminary analysis of the main neurologic complication prevalence reported by the studies was conducted and reported in Figure 2. The main neurologic conditions associated to SARS-CoV-2 were found to be stroke, STDs and encephalopathy. In particular, $41 \%$ of the studies reported stroke as neurological complication $[20,22-27,33,35,37,38,44,47,51,52,54,55,57,58,62,64,65,67-69,71,74,78], 26 \%$ reported STDs $[34,36,40,46,49,50,66,73,75-77,79-85]$ and $18 \%$ reported encephalopathy $[17,30-32,39,42,43,53,67,71,72]$.

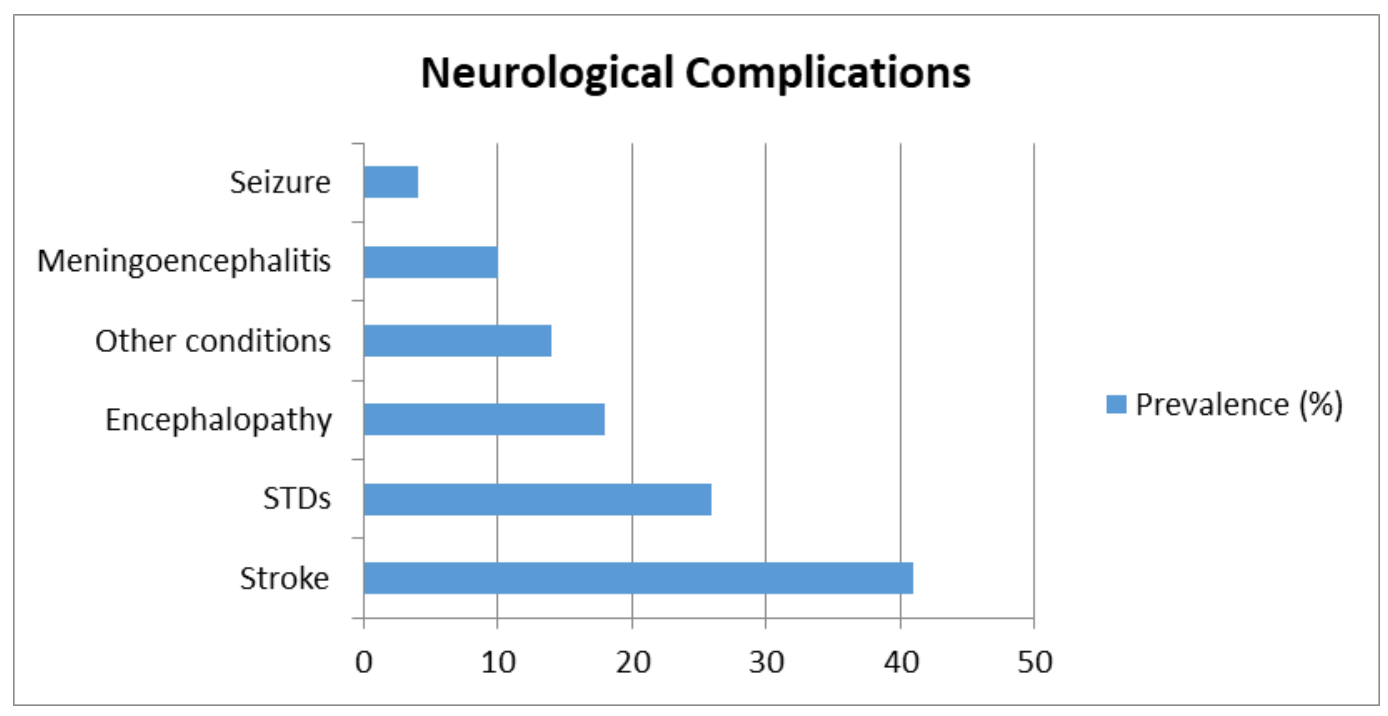

Figure 2. The prevalence of the main neurological complications of SARS-CoV-2 infection reported by the analyzed studies were: stroke (41\%); STDs (26\%); encephalopathy (18\%); meningoencephalitis $(10 \%)$; seizures ( $4 \%)$; and other conditions $(14 \%)$, which included impaired consciousness, brain edema, headache, dizziness, acute mania, intracranial hypertension, EEG alterations, brain demyelination and vasculopathy.

\subsubsection{Effects of SARS-CoV-2 on PNS}

There is a less substantial but still relevant number of studies reporting neurologic complications of COVID-19 such as peripheral neuropathy, myopathy or peripheral demyelinating lesions.

In the aforementioned retrospective observational study carried out by Mao and colleagues [68], neurologic symptoms ascribable to PNS lesions were vision impairment, nerve pain and skeletal muscle pain.

The previously mentioned prospective study, conducted by Karadaş and colleagues [78], also reported peripheral nervous system complications among COVID-19 patients. The most frequent conditions were trigeminal neuralgia, glossopharyngeal neuralgia, vagoglossopharyngeal neuralgia, muscle pain, restless leg syndrome and Guillain-Barré syndrome.

Abdelnour and colleagues [86] reported the case of a 69-year-old man exhibiting numbness on both legs and reduced muscular power as secondary symptoms of SARS-CoV-2 infection. The patient had a past medical history of hypertension, diabetes mellitus and chronic obstructive pulmonary disease.

Homma and colleagues [92] reported the case of a 35-year-old patient who developed facial nerve palsy secondary to COVID-19. She had no pre-existing pathologies but she was a usual smoker. 
Thirteen studies [87,88,90,93,95-102,104] reported an overall number of 17 patients aged between 21 and 71 with a diagnosis of Guillain-Barré syndrome as a complication of COVID-19. None of them had previous medical conditions, except for four patients: the one described by Alberti and colleagues [87] had hypertension, abdominal aortic aneurysm and lung cancer; the patient described by Hutchins and colleagues [93] had herpes simplex virus, hypertension, diabetes and obesity; the patient reported by Rana and colleagues [97] had hypertension, hyperlipidemia and restless leg syndrome; and the one reported by Webb and colleagues [102] had hypertension and psoriasis. When performed, CSF was found to be negative for SARS-CoV-2 infection [87,95,100,104].

Three studies $[89,91,94]$ described Miller Fisher syndrome as another neurologic complication of SARS-CoV-2 infection. Dinkin and colleagues [89] reported two patients, a 71-year-old woman and a 36-year-old man, who developed also ophthalmoparesis. The former had pre-existing hypertension, while the latter had a past medical history of infantile strabismus. The two patients described by Gutierréz-Ortiz and colleagues [91] were two males aged 50 and 39, respectively, and had pre-existing bronchial asthma. Lantos and colleagues [94] reported a 36-year-old man with a medical history of left eye strabismus. All CSF swabs were negative for COVID-19.

Wei and colleagues [103] reported the case of a 61-year-old woman presenting oculomotor nerve palsy as a complication of SARS-CoV-2 infection. She had a past history of alcohol and tobacco addiction and pre-existing medical conditions such as hypertension, type II diabetes and lacunar infarction.

In conclusion, the aim of the present study was to investigate the neurological manifestations in COVID-19 patients, caused by SARS-CoV-2. In total, 86 studies were included and were divided into two categories: studies concerning COVID-19 effects on the CNS $(n=68)$ and those concerning the PNS $(n=21)$. In total, 6890 patients were included in our systematic review.

We observed a growing evidence of the neurological manifestations associated with COVID-19 involving the CNS and PNS.

According to the analyzed studies, the most frequent disorders affecting the CNS were the following: ischemic/hemorrhagic stroke $[20,22-27,33,35,37,38,44,47,51,52,54,55,57,58,62,64,65,67,69,71,74]$, olfactory and taste disorders $[34,36,40,46,49,50,66,73,75-77,79,80,82-85]$, meningoencephalitis $[16,21,28,52,59,60,63]$ and encephalopathy $[3,30,39,67,71,72]$.

As regards the PNS, the most frequent manifestations reported by literature were Guillain-Barré [78,87,88,90,93,95-102,104] and Miller Fisher syndromes [89,91,94].

SARS-CoV-2 neuro-invasiveness is a complex process that probably depends on multiple interacting factors such as viral load, tissue neurotropism and host immune response. Transgenic murine models for SARS-CoV provide a strong basis to help understand SARS-CoV-2 invasion into the nervous system: the virus enters the brain via the olfactory nerve and the cribriform plate of the ethmoid bone, on which the olfactory bulb lies. From this point, the virus spreads to connected brain areas [105]. Furthermore, ACE 2 and TMPRSS2 have been found to be expressed in sustentacular cells, stem cells and perivascular cells of the neuroepithelium, suggesting a crucial role of these cells in virus spread through the olfactory epithelium [106,107]. This mechanism may also explain why one of the most frequent symptoms of COVID-19 is anosmia, on which taste alteration depends [108].

Additionally, in CSF analysis, some studies reported traces of SARS-CoV-2 in the liquor [16,21], whereas others did not [20,60]. In this context, Al Saiegh and colleagues [20] proposed that, in the case of non-fulminant course of the disease, the brain-blood barrier may not be disrupted and consequently the virus does not infect CSF; furthermore, in the case of CSF negativity for SARS-CoV-2, neurologic symptoms might origin from an indirect pathogenic pathway which prevents CSF to be directly infected.

The studies analyzed thus far showed a significant heterogeneity and this aspect was particularly evident in: (1) the clinical profile of the population studied; (2) sample size; (3) study design; and (4) outcome measures employed.

Important clinical information on the neurological manifestations of SARS-CoV-2 would help clinicians raise awareness, and simultaneously improve prognosis of critically ill patients. 


\section{Conclusions}

Due to the statistical heterogeneity among the analyzed studies, a meta-analysis investigation was not possible. Therefore, to minimize possible outcome biases, the adoption of case-control designs in future study protocols is strongly recommended.

Given the rapid evolution of the pandemic emergency and in the light of the increasing amount of clinical data reporting neurologic involvement in COVID-19, further investigations are required to better understand the underlying pathogenic mechanisms of SARS-CoV-2 neuro-invasion. Furthermore, thorough knowledge of the main neurologic features associated with COVID-19 is of particular importance, since some hypotheses have been proposed regarding a possible primary role of the nervous system in determining respiratory symptomatology. Finally, we strongly suggest developing systematic psychological, neurological and neuropsychological examinations of affected patients and efficient follow-up treatments, in order to manage possible long-term effects of neurologic complications, especially in the case of patients with pre-existing cerebrovascular risk factors, and to alleviate the burden of critically ill patients. The Inter-Agency Standing Committee guidelines for mental health and psychosocial support during emergency situations recommend integration of multiple levels of intervention in response to epidemics [109-113].

This could prevent neurodegenerative processes induced by neuroinflammation or stroke-dependent permanent neurologic deficits. Further elucidations in this regard are needed, in order to better understand COVID-19 etiopathogenesis and to better handle COVID-19 patients.

Supplementary Materials: The following are available online at http://www.mdpi.com/1660-4601/17/18/6688/s1, Table S1: Studies concerning COVID-19 effects on the Central Nervous System; Table S2: Studies concerning COVID-19 effects on the Peripheral Nervous System.

Author Contributions: Conceptualization, G.O.; methodology, G.O.; formal analysis, G.O. and C.C.; investigation, G.O.; resources, E.M., F.F. and R.C.; data curation, E.M. and F.F.; writing-original draft preparation, G.O., E.M. and F.F.; writing-review and editing, G.O., E.M. and C.C.; and supervision, A.G. All authors have read and agreed to the published version of the manuscript.

Funding: This research received no external funding.

Conflicts of Interest: The authors declare no conflict of interest.

\section{References}

1. Paules, C.I.; Marston, H.D.; Fauci, A.S. Coronavirus Infections-More Than Just the Common Cold. JAMA 2020, 323, 707-708. [CrossRef] [PubMed]

2. Yu, H.Q.; Sun, B.Q.; Fang, Z.F.; Zhao, J.C.; Liu, X.Y.; Li, Y.M.; Sun, X.Z.; Liang, H.F.; Zhong, B.; Huang, Z.F.; et al. Distinct features of SARS-CoV-2-specific IgA response in COVID-19 patients. Eur. Respir. J. 2020, 56, 2001526. [CrossRef] [PubMed]

3. World Health Organization. Middle East Respiratory Syndrome Coronavirus (MERS-CoV); World Health Organization: Geneva, Switzerland, 2019.

4. Lauer, S.A.; Grantz, K.H.; Bi, Q.; Jones, F.K.; Zheng, Q.; Meredith, H.R.; Azman, A.S.; Reich, N.G.; Lessler, J. The incubation period of coronavirus disease 2019 (COVID-19) from publicly reported confirmed cases: Estimation and application. Ann. Intern. Med. 2020, 172, 577-582. [CrossRef]

5. Huang, C.; Wang, Y.; Li, X.; Ren, L.; Zhao, J.; Hu, Y.; Zhang, L.; Fan, G.; Xu, J.; Gu, X.; et al. Clinical features of patients infected with 2019 novel coronavirus in Wuhan, China. Lancet 2020, 395, 497-506. [CrossRef]

6. Yuan, Y.; Cao, D.; Zhang, Y.; Ma, J.; Qi, J.; Wang, Q.; Lu, G.; Wu, Y.; Yan, J.; Shi, Y.; et al. Cryo-EM structures of MERS-CoV and SARS-CoV spike glycoproteins reveal the dynamic receptor binding domains. Nat. Commun. 2017, 8, 15092. [CrossRef]

7. Zhou, P.; Yang, X.L.; Wang, X.G.; Hu, B.; Zhang, L.; Zhang, W.; Si, H.R.; Zhu, Y.; Li, B.; Huang, C.L.; et al. A pneumonia outbreak associated with a new coronavirus of probable bat origin. Nature 2020, 579, $270-273$. [CrossRef] [PubMed] 
8. Hamming, I.; Timens, W.; Bulthuis, M.L.C.; Lely, A.T.; Navis, G.J.; van Goor, H. Tissue distribution of ACE2 protein, the functional receptor for SARS coronavirus. A first step in understanding SARS pathogenesis. J. Pathol. 2004, 203, 631-637. [CrossRef]

9. Wrapp, D.; Wang, N.; Corbett, K.S.; Goldsmith, J.A.; Hsieh, C.L.; Abiona, O.; Graham, B.S.; McLellan, J.S. Cryo-EM structure of the 2019-nCoV spike in the prefusion conformation. Science 2020, 367, 1260-1263. [CrossRef]

10. Matsuyama, S.; Nao, N.; Shirato, K.; Kawase, M.; Saito, S.; Takayama, I.; Nagata, N.; Sekizuka, T.; Katoh, H.; Kato, F.; et al. Enhanced isolation of SARS-CoV-2 by TMPRSS2-expressing cells. Proc. Natl. Acad. Sci. USA 2020, 117, 7001-7003. [CrossRef]

11. Sungnak, W.; Huang, N.; Bécavin, C.; Berg, M.; Queen, R.; Litvinukova, M.; Talavera-López, C.; Maatz, H.; Reichart, D.; Sampaziotis, F.; et al. SARS-CoV-2 entry factors are highly expressed in nasal epithelial cells together with innate immune genes. Nat. Med. 2020, 26, 681-687. [CrossRef]

12. Tortorici, M.A.; Walls, A.C.; Lang, Y.; Wang, C.; Li, Z.; Koerhuis, D.; Boons, G.J.; Bosch, B.J.; Rey, F.A.; de Groot, R.J.; et al. Structural basis for human coronavirus attachment to sialic acid receptors. Nat. Struct. Mol. Biol. 2019, 26, 481-489. [CrossRef] [PubMed]

13. Hulswit, R.J.G.; Lang, Y.; Bakkers, M.J.G.; Li, W.; Li, Z.; Schouten, A.; Ophorst, B.; van Kuppeveld, F.J.M.; Boons, G.J.; Bosch, B.J.; et al. Human coronaviruses OC43 and HKU1 bind to 9-O-acetylated sialic acids via a conserved receptor-binding site in spike protein domain A. Proc. Natl. Acad. Sci. USA 2019, 116, 2681-2690. [CrossRef]

14. Chen, Z.; Mi, L.; Xu, J.; Yu, J.; Wang, X.; Jiang, J.; Xing, J.; Shang, P.; Qian, A.; Li, Y.; et al. Function of HAb18G/CD147 in invasion of host cells by severe acute respiratory syndrome coronavirus. J. Infect. Dis. 2005, 191, 755-760. [CrossRef] [PubMed]

15. Callaway, E. Labs rush to study coronavirus in trans-genic animals-some are in short supply. Nature 2020, 579, 183. [CrossRef]

16. Moriguchi, T.; Harii, N.; Goto, J.; Harada, D.; Sugawara, H.; Takamino, J.; Ueno, M.; Sakata, H.; Kondo, K.; Myose, N.; et al. A first case of meningitis/encephalitis associated with SARS-Coronavirus-2. Int. J. Infect. Dis. 2020, 94, 55-58. [CrossRef]

17. Poyiadji, N.; Shahin, G.; Noujaim, D.; Stone, M.; Patel, S.; Griffith, B. COVID-19-associated Acute Hemorrhagic Necrotizing Encephalopathy: CT and MRI Features. Radiology 2020, 296, E119-E120. [CrossRef]

18. Paniz-Mondolfi, A.; Bryce, C.; Grimes, Z.; Gordon, R.E.; Reidy, J.; Lednicky, J.; Sordillo, E.M.; Fowkes, M. Central nervous system involvement by severe acute respiratory syndrome coronavirus-2 (SARS-CoV-2). J. Med. Virol. 2020, 92, 699-702. [CrossRef]

19. Moher, D.; Liberati, A.; Tetzlaff, J.; Altman, D.G. Preferred reporting items for systematic reviews and meta-analyses: The PRISMA statement. Ann. Intern. Med. 2009, 151, 264-269. [CrossRef]

20. Al Saiegh, F.; Ghosh, R.; Leibold, A.; Avery, M.B.; Schmidt, R.F.; Theofanis, T.; Mouchtouris, N.; Philipp, L.; Peiper, S.C.; Wang, Z.-X.; et al. Status of SARS-CoV-2 in cerebrospinal fluid of patients with COVID-19 and stroke. Cereb. Dis. 2020, 91, 846-848.

21. Al-olama, M.; Rashid, A.; Garozzo, D. COVID-19-associated meningoencephalitis complicated with intracranial hemorrhage: A case report. Acta Neurochir. 2020, 162, 1495-1499. [CrossRef]

22. Barrios-López, J.M.; Rego-García, I.; Martínez, C.M.; Romero-Fábrega, J.C.; Rodríguez, M.R.; Giménez, J.A.R.; Escamilla-Sevilla, F.; Mínguez-Castellanos, A.; Pérez, M.D.F. Ischaemic stroke and SARS-CoV-2 infection: A causal or incidental association? Neurología 2020, 35, 295-302. [CrossRef] [PubMed]

23. Benger, M.; Williams, O.; Siddiqui, J.; Sztriha, L. Intracerebral haemorrhage and COVID-19: Clinical characteristics from a case series. Brain Behav. Immun. 2020, 88, 940-944. [CrossRef] [PubMed]

24. Beyrouti, R.; Adams, M.E.; Benjamin, L.; Cohen, H.; Farmer, S.F.; Goh, Y.Y.; Humphries, F.; Jäger, H.R.; Losseff, N.A.; Perry, R.J.; et al. Characteristics of ischaemic stroke associated with COVID-19. J. Neurol. Neurosurg. Psychiatry 2020, 91, 889-891. [CrossRef]

25. Co, C.O.C.; Yu, J.R.T.; Laxamana, L.C.; David-Ona, D.I.A. Intravenous Thrombolysis for Stroke in a COVID-19 Positive Filipino Patient, a Case Report. J. Clin. Neurosci. 2020, 77, 234-236. [CrossRef] [PubMed]

26. Craen, A.; Logan, G.; Ganti, L. Novel Coronavirus Disease 2019 and Subarachnoid Hemorrhage: A Case Report. Cureus 2020, 12, e7846. [CrossRef] 
27. Deliwala, S.; Abdulhamid, S.; Abusalih, M.F.; Al-Qasmi, M.M.; Bachuwa, G. Encephalopathy as the Sentinel Sign of a Cortical Stroke in a Patient Infected With Coronavirus Disease-19 (COVID-19). Cureus 2020, 12, e8121. [CrossRef]

28. Duong, L.; Xu, P.; Liu, A. Meningoencephalitis without respiratory failure in a young female patient with COVID-19 infection in Downtown Los Angeles, early April 2020. Brain Behav. Immun. 2020, 87, 33. [CrossRef]

29. Fasano, A.; Cavallieri, F.; Canali, E.; Valzania, F. First motor seizure as presenting symptom of SARS-CoV-2 infection. Neurol. Sci. 2020, 41, 1651-1653. [CrossRef]

30. Filatov, A.; Sharma, P.; Hindi, F.; Espinosa, P.S. Neurological Complications of Coronavirus Disease (COVID-19). Encephalopathy. Cureus 2020, 12, e7352. [CrossRef]

31. Flamand, M.; Perron, A.; Buron, Y.; Szurhaj, W. Pay more attention to EEG in COVID-19 pandemic. Clin. Neurophysiol. 2020, 131, 2062-2064. [CrossRef]

32. Franceschi, A.M.; Ahmed, O.; Giliberto, L.; Castillo, M. Hemorrhagic Posterior Reversible Encephalopathy Syndrome as a Manifestation of COVID-19 Infection. Am. J. Neuroradiol. 2020, 41, 1173-1176. [CrossRef] [PubMed]

33. Frisullo, G.; Bellavia, S.; Scala, I.; Piano, C.; Morosetti, R.; Brunetti, V.; Calabresi, P.; Marca, G.D. Stroke and COVID19: Not only a large-vessel disease. J. Stroke Cereb. Dis. 2020, 29, 105074. [CrossRef] [PubMed]

34. Gane, S.B.; Kelly, C.; Hopkins, C. Isolated sudden onset anosmia in COVID-19 infection. A novel syndrome? Rhinology 2020, 58, 299-301. [CrossRef] [PubMed]

35. Garaci, F.; Giuliano, F.D.; Picchi, E.; Ros, V.D.; Floris, R. Venous cerebral thrombosis in COVID-19 patient. J. Neurol. Sci. 2020, 414, 116871. [CrossRef] [PubMed]

36. Gilani, S.; Roditi, R.; Naraghi, M. COVID-19 and anosmia in Tehran, Iran. Med. Hypotheses 2020, $141,109757$. [CrossRef]

37. Goldberg, M.F.; Goldberg, M.F.; Cerejo, R.; Tayal, A.H. Cerebrovascular Disease in COVID-19. Am. J. Neuroradiol. 2020, 41, 1170-1172. [CrossRef]

38. Haddadi, K.; Ghasemian, R.; Shafizad, M. Basal Ganglia Involvement and Altered Mental Status: A Unique Neurological Manifestation of Coronavirus Disease 2019. Cureus 2020, 12, e7869. [CrossRef]

39. Hayashi, M.; Sahashi, Y.; Baba, Y.; Okura, H.; Shimohata, T. COVID-19 associated mild encephalitis/encephalopathy with a reversible splenial lesion. J. Neurol. Sci. 2020, 415, 116941. [CrossRef]

40. Hjelmesæth, J.; Skaare, D. Loss of smell or taste as the only symptom of COVID-19. Tidsskr Nor Legeforen 2020, 140. [CrossRef]

41. Kadono, Y.; Nakamura, Y.; Ogawa, Y.; Yamamoto, S.; Kajikawa, R.; Nakajima, Y.; Matsumoto, M.; Kishima, H. A case of COVID-19 infection presenting with a seizure following severe brain edema. Seizure Eur. J. Epilepsy 2020, 80, 53-55. [CrossRef]

42. Kaya, Y.; Karab, S.; Akincic, C.; Kocamana, A.S. Transient cortical blindness in COVID-19 pneumonia; a PRES-like syndrome: Case report. J. Neurol. Sci. 2020, 413, 116858. [CrossRef]

43. Kishfy, L.; Casasola, M.; Banankhah, P.; Parvez, A.; Jan, Y.J.; Shenoy, A.M.; Thomson, C.; AbdelRazek, M.A. Posterior reversible encephalopathy syndrome (PRES) as a neurological association in severe Covid-19. J. Neurol. Sci. 2020, 414, 116943. [CrossRef] [PubMed]

44. Manganelli, F.; Vargas, M.; Iovino, A.; Iacovazzo, C.; Santoro, L.; Servillo, G. Brainstem involvement and respiratory failure in COVID-19. Neurol. Sci. 2020, 41, 1663-1665. [CrossRef] [PubMed]

45. Mawhinney, J.A.; Wilcock, C.; Haboubi, H.; Roshanzamir, S. Neurotropism of SARS-CoV-2: COVID-19 presenting with an acute manic episode. BMJ Case Rep. 2020, 13, e236123. [CrossRef] [PubMed]

46. Melley, L.E.; Bress, E.; Polan, E. Hypogeusia as the initial presenting symptom of COVID-19. BMJ Case Rep. 2020, 13, 236080. [CrossRef] [PubMed]

47. Muhammad, S.; Petridis, A.; Cornelius, J.F.; Hänggi, D. Letter to editor: Severe brain haemorrhage and concomitant COVID-19 Infection: A neurovascular complication of COVID-19. Brain Behav. Immun. 2020, 87, 150-151. [CrossRef] [PubMed]

48. Noro, F.; de Mendonça Cardoso, F.; Marchiori, E. COVID-19 and benign intracranial hypertension: A case report. J. Braz. Soc. Trop. Med. 2020, 53, e20200325. [CrossRef]

49. Ollarves-Carrero, M.F.; Rodriguez-Morales, A.G.; Bonilla-Aldana, D.K.; Rodriguez-Morales, A.J. Anosmia in a healthcare worker with COVID-19 in Madrid, Spain. Travel Med. Infect. Dis. 2020, 35, 101666. [CrossRef]

50. Ottaviano, G.; Carecchio, M.; Scarpa, B.; Marchese-Ragona, R. Olfactory and rhinological evaluations in SARS-CoV-2 patients complaining of olfactory loss. Rhinology 2020, 58, 400-401. [CrossRef] 
51. Oxley, T.J.; Mocco, J.; Majidi, S.; Kellner, C.P.; Shoirah, H.; Singh, I.P.; Leacy, R.A.D.; Shigematsu, T.; Ladner, T.R.; Yaeger, K.A.; et al. Large-Vessel Stroke as a Presenting Feature of Covid-19 in the Young. N. Engl. J. Med. 2020, 382, e60. [CrossRef]

52. Reichard, R.R.; Kashani, K.B.; Boire, N.A.; Constantopoulos, E.; Guo, Y.; Lucchinetti, C.F. Neuropathology of COVID-19: A spectrum of vascular and acute disseminated encephalomyelitis (ADEM)-like pathology. Acta Neuropathol. 2020, 140, 1-6. [CrossRef] [PubMed]

53. Rogg, J.; Baker, A.; Tung, G. Posterior reversible encephalopathy syndrome (PRES): Another imaging manifestation of COVID-19. Interdiscip. Neurosurg. 2020, 22, 100808. [CrossRef] [PubMed]

54. Sharifi-Razavi, A.; Karimi, N.; Rouhani, N. COVID-19 and intracerebral haemorrhage: Causative or coincidental? New Microbes New Infect. 2020, 35, 100669. [CrossRef] [PubMed]

55. Shoskes, A.; Migdady, I.; Fernandez, A.; Ruggieri, P.; Rae-Grant, A. Cerebral Microhemorrhage and Purpuric Rash in COVID-19: The Case for a Secondary Microangiopathy. J. Stroke Cereb. Dis. 2020, 29, 105111. [CrossRef]

56. Somani, S.; Pati, S.; Gaston, T.; Chitlangia, A.; Agnihotri, S. De Novo Status Epilepticus in patients with COVID-19. Ann. Clin. Transl. Neurol. 2020, 7, 1240-1244. [CrossRef]

57. Tunç, A.; Ünlübaş, Y.; Alemdar, M.; Akyüz, E. Coexistence of COVID-19 and acute ischemic stroke report of four cases. J. Clin. Neurosci. 2020, 77, 227-229. [CrossRef]

58. Viguier, A.; Delamarre, L.; Duplantier, J.; Olivot, J.M.; Bonneville, F. Acute ischemic stroke complicating common carotid artery thrombosis during a severe COVID-19 infection. J. Neuroradiol. 2020, 47, 393-394. [CrossRef]

59. Wong, P.F.; Craik, S.; Newman, P.; Makan, A.; Srinivasan, K.; Crawford, E.; Dev, D.; Moudgil, H.; Ahmad, N. Lessons of the month 1: A case of rhombencephalitis as a rare complication of acute COVID-19 infection. Clin. Med. 2020, 20, 293-294. [CrossRef]

60. Ye, M.; Ren, Y.; Lv, T. Encephalitis as a clinical manifestation of COVID-19. Brain Behav. Immun. 2020, 88, 945-946. [CrossRef]

61. Zanin, L.; Saraceno, G.; Panciani, P.P.; Renisi, G.; Signorini, L.; Migliorati, K.; Fontanella, M.M. SARS-CoV-2 can induce brain and spine demyelinating lesions. Acta Neurochir. 2020, 162, 1491-1494. [CrossRef]

62. Zhai, P.; Ding, Y.; Li, Y. The impact of COVID-19 on ischemic stroke. Diagn. Pathol. 2020, 15, 78. [CrossRef]

63. Zoghi, A.; Ramezani, M.; Roozbeh, M.; Darazam, I.A.; Sahraian, M.A. A case of possible atypical demyelinating event of the central nervous system following COVID-19. Mult. Scler. Relat. Disord. 2020, 44, 102324. [CrossRef] [PubMed]

64. Avula, A.; Nalleballe, K.; Narula, N.; Sapozhnikov, S.; Dandu, V.; Toom, S.; Glaser, A.; Elsayegh, D. COVID-19 presenting as stroke. Brain Behav. Immun. 2020, 87, 115-119. [CrossRef] [PubMed]

65. Kandemirli, S.G.; Dogan, L.; Sarikaya, Z.T.; Kara, S.; Akinci, C.; Kaya, D.; Kaya, Y.; Yildirim, D.; Tuzuner, F.; Yildirim, M.S.; et al. Brain MRI Findings in Patients in the Intensive Care Unit with COVID-19 Infection. Radiology 2020. [CrossRef] [PubMed]

66. Lechien, J.R.; Chiesa-Estomba, C.M.; Siati, D.R.D.; Horoi, M.; Bon, S.D.L.; Rodriguez, A.; Dequanter, D.; Blecic, S.; Afia, F.E.; Distinguin, L.; et al. Olfactory and gustatory dysfunctions as a clinical presentation of mild-to-moderate forms of the coronavirus disease (COVID-19): A multicenter European study. Rhinology 2020, 277, 2251-2261.

67. Lu, L.; Xiong, W.; Liu, D.; Liu, J.; Yang, D.; Li, N.; Mu, J.; Guo, J.; Li, W.; Wang, G.; et al. New onset acute symptomatic seizure and risk factors in coronavirus disease 2019: A retrospective multicenter study. Epilepsia 2020, 61, e49-e53. [CrossRef]

68. Mao, L.; Jin, H.; Wang, M.; Hu, Y.; Chen, S.; He, Q.; Chang, J.; Hong, C.; Zhou, Y.; Wang, D.; et al. Neurologic Manifestations of Hospitalized Patients With Coronavirus Disease. JAMA Neurol. 2020, 77, 683-690. [CrossRef]

69. Morassi, M.; Bagatto, D.; Cobelli, M.; D’Agostini, S.; Gigli, G.L.; Bnà, C.; Vogrig, A. Stroke in patients with SARS-CoV-2 infection: Case series. J. Neurol. 2020, 267, 2185-2192. [CrossRef]

70. Petrescu, A.M.; Taussig, D.; Bouilleret, V. Electroencephalogram (EEG) in COVID-19: A systematic retrospective study. Clin. Neurophysiol. 2020, 50, 155-165. [CrossRef]

71. Radmanesh, A.; Derman, A.; Lui, Y.W.; Raz, E.; Loh, J.P.; Hagiwara, M.; Borja, M.J.; Zan, E.; Fatterpekar, G.M. COVID-19 associated Diffuse Leukoencephalopathy and Microhemorrhages. Radiology 2020. [CrossRef] 
72. Scullen, T.; Keen, J.; Mathkour, M.; Dumont, A.S.; Kahn, L. Coronavirus 2019 (COVID-19)-Associated Encephalopathies and Cerebrovascular Disease: The New Orleans Experience. World Neurosurg. 2020, 141, e437-e446. [CrossRef] [PubMed]

73. Spinato, G.; Fabbris, C.; Polesel, J.; Cazzador, D.; Borsetto, D.; Hopkins, C.; Boscolo-Rizzo, P. Alterations in Smell or Taste in Mildly Symptomatic Outpatients With SARS-CoV-2 Infection. JAMA 2020, 323, 2089-2090. [CrossRef] [PubMed]

74. Helms, J.; Kremer, S.; Merdji, H.; Clere-Jehl, R.; Schenck, M.; Kummerlen, C.; Collange, O.; Boulay, C.; Fafi-Kremer, S.; Ohana, M.; et al. Neurologic Features in Severe SARS-CoV-2 Infection. N. Engl. J. Med. 2020, 382, 2268-2270. [CrossRef] [PubMed]

75. Hopkins, C.; Surda, P.; Whitehead, E.; Kumar, B.N. Early recovery following new onset anosmia during the COVID-19 pandemic-An observational cohort study. J. Otolaryngol.-Head Neck Surg. 2020, 49, 26. [CrossRef] [PubMed]

76. Vaira, L.A.; Deiana, G.; Fois, A.G.; Pirina, P.; Madeddu, G.; Vito, A.D.; Babudieri, S.; Petrocelli, M.; Serra, A.; Bussu, F.; et al. Objective evaluation of anosmia and ageusia in COVID-19 patients: Single-center experience on 72 cases. Head Neck 2020, 42, 1252-1258. [CrossRef] [PubMed]

77. Vaira, L.A.; Hopkins, C.; Petrocelli, M.; Lechien, J.R.; Chiesa-Estomba, C.M.; Salzano, G.; Cucurullo, M.; Salzano, F.A.; Saussez, S.; Boscolo-Rizzo, P.; et al. Smell and taste recovery in coronavirus disease 2019 patients: A 60-day objective and prospective study. J. Laryngol. Otol. 2020, 12, 1-7. [CrossRef]

78. Karadaş, Ö.; Öztürk, B.; Sonkaya, A.R. A prospective clinical study of detailed neurological manifestations in patients with COVID-19. Neurol. Sci. 2020, 41, 1991-1995. [CrossRef]

79. Lee, Y.; Min, P.; Lee, S.; Kim, S.W. Prevalence and Duration of Acute Loss of Smell or Taste in Covid-19 Patients. J. Korean Med. Sci. 2020, 35, e174. [CrossRef]

80. Speth, M.M.; Singer-Cornelius, T.; Oberle, M.; Gengler, I.; Brockmeier, S.J.; Sedaghat, A.R. Olfactory Dysfunction and Sinonasal Symptomatology in COVID-19: Prevalence, Severity, Timing, and Associated Characteristics. Otolaryngol.-Head Neck Surg. 2020, 163, 114-120. [CrossRef]

81. Beltrán-Corbellini, A.; Chico-García, J.L.; Martínez-Poles, J.; Rodríguez-Jorge, F.; Natera-Villalba, E.; Gómez-Corral, J.; Gómez-López, A.; Monreal, E.; Parra-Díaz, P.; Cortés-Cuevas, J.L.; et al. Acute-onset smell and taste disorders in the context of COVID-19: A pilot multicentre polymerase chain reaction based case-control study. Eur. J. Neurol. 2020. [CrossRef]

82. Carignan, A.; Valiquette, L.; Grenier, C.; Musonera, J.B.; Nkengurutse, D.; Marcil-Héguy, A.; Vettese, K.; Marcoux, D.; Valiquette, C.; Xiong, W.T.; et al. Anosmia and dysgeusia associated with SARS-CoV-2 infection: An age-matched case-control study. Can. Med. Assoc. J. 2020, 192, E702-E707. [CrossRef] [PubMed]

83. Hornuss, D.; Lange, B.; Schröter, N.; Rieg, S.; Kern, W.V.; Wagner, D. Anosmia in COVID-19 patients. Clin. Microbiol. Infect. 2020. [CrossRef] [PubMed]

84. Dell'Era, V.; Farri, F.; Garzaro, G.; Gatto, M.; Aluffi Valletti, P.; Garzaro, M. Smell and taste disorders during COVID-19 outbreak: A cross-sectional study on 355 patients. Head Neck 2020, 42, 1591-1596. [CrossRef] [PubMed]

85. Giacomelli, A.; Pezzati, L.; Conti, F.; Bernacchia, D.; Siano, M.; Oreni, L.; Rusconi, S.; Gervasoni, C.; Ridolfo, A.L.; Rizzardini, G.; et al. Self-reported Olfactory and Taste Disorders in Patients With Severe Acute Respiratory Coronavirus 2 Infection: A Cross-sectional Study. Clin. Infect. Dis. 2020, 71, 889-890. [CrossRef]

86. Abdelnour, L.; Abdalla, M.E.; Babiker, S. COVID 19 infection presenting as motor peripheral neuropathy. J. Formos. Med. Assoc. 2020, 119, 1119-1120. [CrossRef]

87. Alberti, P.; Beretta, S.; Piatti, M.; Karantzoulis, A.; Piatti, M.L.; Santoro, P.; Viganò, M.; Giovannelli, G.; Pirro, F.; Montisano, D.A.; et al. Guillain-Barré syndrome related to COVID-19 infection. Neurol. Neuroimmunol. Neuroinflammation 2020, 7, e741. [CrossRef] [PubMed]

88. Coen, M.; Jeanson, G.; Almeida, L.A.C.; Hübers, A.; Stierlin, F.; Najjar, I.; Ongaro, M.; Moulin, K.; Makrygianni, M.; Leemann, B.; et al. Guillain-Barré syndrome as a complication of SARS-CoV-2 infection. Brain Behav. Immun. 2020, 87, 111-112. [CrossRef]

89. Dinkin, M.; Gao, V.; Kahan, J.; Bobker, S.; Simonetto, M.; Wechsler, P.; Harpe, J.; Greer, C.; Mints, G.; Salama, G.; et al. COVID-19 presenting with ophthalmoparesis from cranial nerve palsy. Neurology 2020, 95, 221-223. [CrossRef]

90. Farzi, M.A.; Ayromlou, H.; Jahanbakhsh, N.; Bavil, P.H.; Janzadeh, A.; Shayan, F.K. Guillain-Barré syndrome in a patient infected with SARS-CoV-2, a case report. J. Neuroimmunol. 2020, 346, 577294. [CrossRef] 
91. Gutiérrez-Ortiz, C.; Méndez, A.; Rodrigo-Rey, S.; Pedro-Murillo, E.S.; Bermejo-Guerrero, L.; Gordo-Mañas, R.; Aragón-Gómez, F.D.; Benito-León, J. Miller Fisher Syndrome and polyneuritis cranialis in COVID-19. Neurology 2020, 95, e601-e605. [CrossRef]

92. Homma, Y.; Watanabe, M.; Inoue, K.; Moritaka, T. Coronavirus Disease-19 Pneumonia with Facial Nerve Palsy and Olfactory Disturbance. Intern. Med. 2020, 59, 1773-1775. [CrossRef] [PubMed]

93. Hutchins, K.L.; Jansen, J.H.; Comer, A.D.; Scheer, R.V.; Zahn, G.S.; Capps, A.E.; Weaver, L.M.; Koontz, N.A. COVID-19 Associated Bifacial Weakness with Paresthesia Subtype of Guillain-Barré Syndrome. Am. J. Neuroradiol. 2020. [CrossRef] [PubMed]

94. Lantos, J.E.; Strauss, S.B.; Lin, E. COVID-19 Associated Miller Fisher Syndrome: MRI Findings. Am. J. Neuroradiol. 2020, 41, 1184-1186. [CrossRef]

95. Ottaviani, D.; Boso, F.; Tranquillini, E.; Gapeni, I.; Pedrotti, G.; Cozzio, S.; Guarrera, G.M.; Giometto, B. Early Guillain-Barré syndrome in coronavirus disease 2019 (COVID-19): A case report from an Italian COVID-hospital. Neurol. Sci. 2020, 41, 1351-1354. [CrossRef] [PubMed]

96. Padroni, M.; Mastrangelo, V.; Asioli, G.M.; Pavolucci, L.; Abu-Rumeileh, S.; Piscaglia, M.G.; Querzani, P.; Callegarini, C.; Foschi, M. Guillain-Barré syndrome following COVID-19: New infection, old complication? J. Neurol. 2020, 267, 1877-1879. [CrossRef]

97. Rana, S.; Lima, A.A.; Chandra, R.; Valeriano, J.; Desai, T.; Freiberg, W.; Small, G. Novel Coronavirus (COVID-19)-Associated Guillain-Barré Syndrome. J. Clin. Neuromuscul. Dis. 2020, 21, 240-242. [CrossRef]

98. Sedaghat, Z.; Karimi, N. Guillain Barre syndrome associated with COVID-19 infection: A case report. J. Clin. Neurosci. 2020, 76, 233-235. [CrossRef]

99. Scheidl, E.; Canseco, D.D.; Hadji-Naumov, A.; Bereznai, B. Guillain-Barré syndrome during SARS-CoV-2 pandemic: A case report and review of recent literature. J. Peripher. Nerv. Syst. 2020, 25, 204-207. [CrossRef]

100. Toscano, G.; Palmerini, F.; Ravaglia, S.; Ruiz, L.; Invernizzi, P.; Cuzzoni, M.G.; Franciotta, D.; Baldanti, F.; Daturi, R.; Postorino, P.; et al. Guillain-Barré Syndrome Associated with SARS-CoV-2. N. Engl. J. Med. 2020, 382, 2574-2576. [CrossRef]

101. Virani, A.; Rabold, E.; Hanson, T.; Haag, A.; Elrufay, R.; Cheema, T.; Balaan, M.; Bhanot, N. Guillain-Barré Syndrome associated with SARS-CoV-2 infection. IDCases 2020, 20, e00771. [CrossRef]

102. Webb, S.; Wallace, V.C.; Martin-Lopez, D.; Yogarajah, M. Guillain-Barré syndrome following COVID-19: A newly emerging post-infectious complication. BMJ Case Rep. 2020, 13, e236182. [CrossRef]

103. Wei, H.; Yin, H.; Huang, M.; Guo, Z. The 2019 novel coronavirus pneumonia with onset of oculomotor nerve palsy: A case study. J. Neurol. 2020, 267, 1550-1553. [CrossRef] [PubMed]

104. Zhao, H.; Shen, D.; Zhou, H.; Liu, J.; Chen, S. Guillain-Barré syndrome associated with SARS-CoV-2 infection: Causality or coincidence? Lancet 2020, 19, 383-384. [CrossRef]

105. Netland, J.; Meyerholz, D.K.; Moore, S.; Cassell, M.; Perlman, S. Severe Acute Respiratory Syndrome Coronavirus Infection Causes Neuronal Death in the Absence of Encephalitis in Mice Transgenic for Human ACE2. J. Virol. 2008, 82, 7264-7275. [CrossRef] [PubMed]

106. Brann, D.H.; Tsukahara, T.; Weinreb, C.; Lipovsek, M.; den Berge, K.V.; Gong, B.; Chance, R.; Macaulay, I.C.; Chou, H.J.; Fletcher, R.B.; et al. Non-neuronal expression of SARS-CoV-2 entry genes in the olfactory system suggests mechanisms underlying COVID-19-associated anosmia. Sci. Adv. 2020, 6, eabc5801. [CrossRef]

107. Fodoulian, L.; Tuberosa, J.; Rossier, D.; Landis, B.N.; Carleton, A.; Rodriguez, I. SARS-CoV-2 receptor and entry genes are expressed by sustentacular cells in the human olfactory neuroepithelium. BioRxiv 2020. [CrossRef]

108. Ralli, M. Defining the burden of olfactory dysfunction in COVID-19 patients. Eur. Rev. Med. Pharmacol. Sci. 2020, 24, 3440-3441. [PubMed]

109. Orrù, G.; Ciacchini, R.; Gemignani, A.; Conversano, C. Psychological intervention measures during the COVID-19 pandemic. Clin. Neuropsychiatry 2020, 17, 76-79.

110. Marazziti, D.; Pozza, A.; Di Giuseppe, M.; Conversano, C. The psychosocial impact of COVID-19 pandemic in Italy: A lesson for mental health prevention in the first severely hit European country. Psychol. Trauma Theory Res. Pract. Policy 2020, 12, 531-533. [CrossRef]

111. Muratori, P.; Ciacchini, R. Children and the COVID-19 transition: Psychological reflections and suggestions on adapting to the emergency. Clin. Neuropsychiatry 2020, 17, 131-134. 
112. Di Giuseppe, M.; Gemignani, A.; Conversano, C. Psychological resources against the traumatic experience of COVID-19. Clin. Neuropsychiatry 2020, 17, 85-87.

113. Conversano, C.; Marchi, L.; Miniati, M. Psychological distress among healthcare professionals involved in the covid-19 emergency: Vulnerability and resilience factors. Clin. Neuropsychiatry 2020, 17, 94-96.

(C) 2020 by the authors. Licensee MDPI, Basel, Switzerland. This article is an open access article distributed under the terms and conditions of the Creative Commons Attribution (CC BY) license (http://creativecommons.org/licenses/by/4.0/). 